\title{
FROM AUCTION THEORY TO MARKET DESIGN: PAUL MILGROM AND ROBERT WILSON'S CONTRIBUTIONS TO ECONOMICS ${ }^{\circ}$
}

\author{
DE TEORÍA DE SUBASTAS A DISEÑO DE \\ MERCADOS: LAS CONTRIBUCIONES DE PAUL \\ MILGROM Y ROBERT WILSON A LA ECONOMÍA
}

\author{
Leandro Arozamena* \\ Andrés Fioriti** \\ Federico Weinschelbaum ${ }^{* * *}$
}

enviado: 27 octubre 2020 - aprobado: 04 diciembre 2020

\begin{abstract}
Resumen
El premio Nobel de Economía del 2020 fue otorgado a Paul Milgrom y Robert Wilson. Ambos ganadores han realizado contribuciones seminales y cruciales a la teoría de subastas y al diseño práctico de mercados. En esta nota describimos dichas contribuciones y su significatividad dentro del contexto general de la teoría de subastas y en términos prácticos. También realizamos una revisión acerca de contribuciones sustanciales y muy influyentes de los galardonados en otras áreas de la Economía.
\end{abstract}

Palabras clave: subastas, diseño de mecanismos, diseño de mercados. Códigos JEL: C72, D82, D44

Arozamena, L., Fioriti, A., \& Weinschelbaum, F. (2021). From Auction Theory to Market Design: Paul Milgrom and Robert Wilson's Contributions to Economics. Estudios económicos, 38(76), pp 279-296.

* Universidad Torcuato Di Tella and CONICET, Argentina. ORCID N 0000-0002-5104-3735.

** Universidad Nacional del Sur and INMABB, CONICET, Argentina. E-mail: andres.fioriti@uns.edu.ar. ORCID N ${ }^{\circ}$ 0000-0002-6771-0643

*** Universidad Torcuato Di Tella and CONICET, Argentina. ORCID Nº000-0002-4008-1787 


\begin{abstract}
The 2020 Economics Nobel Prize was awarded to Paul Milgrom and Robert Wilson. Both laureates have made seminal, crucial contributions to auction theory and practical market design. Here, we briefly describe those contributions and their significance within the general context of auction theory and practice. We also review the laureates' substantial and highly influential work in other areas of economics.
\end{abstract}

Keywords: auctions, mechanism design, market design.

JEL Codes: C72, D82, D44. 


\section{INTRODUCTION}

The 2020 Sveriges Riksbank Prize in Economic Sciences in Memory of Alfred Nobel was awarded to Paul Milgrom and Robert Wilson, both from Stanford University. In its announcement ${ }^{1}$, the Royal Swedish Academy of Sciences pointed at the crucial contributions both laureates have made to improving our theoretical understanding of auctions and to the creation of new, practically useful auction formats.

Auctions are not a new institution. They have been reported at least since ancient Mesopotamia. Cassidy (1967) provides a detailed historical account of their use since classical antiquity. Today, they are ubiquitous. Their presence ranges from privatizations and spectrum allocation, to public procurement, to electricity markets, to pollution permits, to electronic transactions, to advertisement positions every time a user makes a Google search.

In essence, auctions are a process of price discovery. When there are no available markets where current prices may provide readily available information about the value of an object or a contract, auctions may play that role.

Substantial progress has been made since the last decades of the $20^{\text {th }}$ century in our understanding of how auctions work and which auction formats are appropriate for each context. Auction theory emerged as a dynamic field, and theoretical contributions have been instrumental in allowing and motivating the dramatic increase in the use of auctions in practice. It is hard to find theoretical developments that have had such a deep and immediate effect in actual markets in such a brief period.

Paul Milgrom and Robert Wilson have been pioneers in both aspects of the study of auctions -theory and design. Both in their theoretical research on auctions and their involvement in actual auctions starting in the 1990's, Milgrom and Wilson provided the foundations of how auction theory and design are viewed today. Moreover, both economists deepened our knowledge about other, related topics, such as: trade, pricing, incentives, contract theory, information economics and game theory. It should be said, then, that the fact that they were awarded the Nobel prize came as no surprise.

1 See Royal Swedish Academy of Sciences (2020). 
Here, we will briefly try to introduce the areas where Milgrom and Wilson have made their most significant contributions, and summarize the relevance of those contributions as well. We will do so in the following steps. In Section I, we describe the challenges faced by the theoretical analysis of auctions, focusing on Milgrom and Wilson's key contributions to the field. In Section II we move on to their path-breaking involvement in auctions for spectrum allocation. As we mentioned above, Milgrom and Wilson made highly significant contributions outside the realm of auction theory and practice, some of which we summarize in Section III. We conclude in Section IV.

\section{THEORETICAL ANALYSIS OF AUCTIONS}

\section{I.1. From mechanisms to auctions}

Auctions are special cases of mechanisms. Then, auction theory has both borrowed from and been one of the prime examples and applications of mechanism design theory ${ }^{2}$. In general terms, the starting point for mechanism design theory is a situation where a decision has to be made based on information that is held privately by individuals in a group. Say, for example, that a committee has to select one representative from a list of candidates; different jobs or vacancies in different schools have to be allocated to interested workers or students; or a good, service or contract has to be awarded to an individual or firm that would like to purchase it.

In all these cases, rules have to be set as to how the decision will be made, and given those rules the actual result will depend crucially on all parties' private information -only each committee member knows which candidate she prefers or some of the candidate's characteristics, only each student knows which school she would like to attend, only each buyer knows how much he would be willing to pay. In general, we cannot expect to ask each participant what his private information is and receive a truthful answer. Buyers, for instance, will have a strong incentive to hide their true willingness to pay if it is high.

A mechanism, then, is the set of rules -technically, a game form- used to resolve this issue. In essence, we make agents play a game and examine what the equilibria of that game are when the parties involved act according to their true preference. From that starting point, we can follow two alternative paths. First, we can study actual

2 For a general introduction to the theory of mechanism design, see, for example, Börgers and Krahmer (2015). 
mechanisms - e.g. voting rules, vacancy allocation schemes, auctions- and see how they perform. Second, we can try to identify mechanisms that are optimal according to a criterion imposed by a mechanism designer -e.g. allocation efficiency, or seller revenue. In 2007, the Nobel Prize was awarded to Leonid Hurwicz, Eric Maskin and Roger Myerson for their contributions to mechanism design theory. That theory made substantial progress in identifying what mechanism designers can and cannot achieve given the key limitations that agents' preferences and private information pose to them.

One of the most prominent examples of situations where mechanisms are relevant is that of allocating a set of goods, services, rights or contracts to one or several agents that express their interest in being awarded one or several items in that set. This covers a wide variety of contexts, from selling a work of art, or allocating pollution permits or financial assets, to public procurement. It is in these cases that auctions come into play. In an auction, those interested in receiving the object(s) to be allocated submit bids, which are generally given by sums of money.

Although this may seem to be a specific set of cases, it includes a variety of situations in which very different auction formats are appropriate. One of the key lessons from auction theory and practice is that there is no one-size-fits-all solution. Instead, we have come to understand which types of auctions may perform better in each specific context.

\section{I.2. Auction Theory: The Devil is in the Details ${ }^{3}$}

Just as with mechanisms in general, we may follow two related approaches when studying auction formats. First, we can take the auction format as given and see the equilibria that follow if we use it -i.e. who wins, how much he pays- in different settings. Alternatively, we may take the context as given and try to find out which is the optimal auction format according to a specific objective we may have. In auctioning contexts, two main objectives make sense and have been widely studied in the literature: maximizing the seller's revenue ${ }^{4}$ and achieving efficiency in the allocation -namely, that the object(s) end up in the hands of those that generate most value for society.

Both approaches yield very different answers, depending on the context we are dealing with. Basically, the auction setting, that is, the game bidders play when

3 For a rigorous introduction to auction theory, see Krishna (2009).

4 Naturally, if we are looking at a procurement context, the objective will be minimizing the buyer's cost. 
they take part in an auction, depends on (i) the specific auction format being used, (ii) bidders' characteristics, (iii) the actual objet(s) being auctioned. Do we use an open auction format, where bids are public, or are bids private? How do bidders' valuations for the auctioned object relate to one another? Is it a single object that we are auctioning or are we allocating multiple objects instead?

These questions, and others, have multiple possible answers. Let us now examine some of those answers and see how they relate to one another and how they influence the auctioning context they define.

\section{(1) Auction formats}

Given the diversity of practical situations where auctions are used and have been used in history, there is a wide variety of auction formats that have been studied from a theoretical standpoint. As a guide, let us make the most basic distinction, that between open and closed auctions.

In an open auction, bids are announced publicly. If there is a single object on sale, bidders must somehow announce a prize that they are willing to pay, and the precise format determines who wins. Two classic single-object formats are English and Dutch auctions. In an English, or ascending-price auction, the starting price is low. Then, potential buyers bid against one another by publicly announcing bids that have to topple the highest price previously offered. The auction ends when the highest bid is not raised, the highest bidder wins and pays her bid. In a Dutch, or descending-price auction, the starting price is high and starts falling automatically, until one of the bidders publicly announces that she is willing to pay the standing price. That bidder wins and pays the price at which she stopped the process.

In a closed auction, however, bids are secretly submitted to the auctioneer. A given rule then compares those bids and determines the winner and the price she has to pay. When one object is allocated, the most usual format within this class is the first-price sealed-bid auction. There, the bidder with the highest bid wins, and pays a price equal to her own bid. In a second-price auction, however, the bidder with the highest bid wins as well, but pays a price equal to the second-highest bid. Second-price auctions were studied by Vickrey (1961). Reserve prices, i.e. minimum acceptable bids, can be added to both formats.

First-price sealed-bid auctions and Dutch auctions are strategically equivalent. In the game both auctions generate, each bidder has to choose a number (a bid 
to submit in the first-price auction, and a price at which the bidder will stop the auction in the Dutch format). The bidder choosing the highest number wins, and pays a sum equal to that number. The same allocation follows, and all parties involved then have the same utility in the two formats. Although not in the strategic sense, the second-price and English auctions are equivalent as well. Under private values they also generate the same allocation and payoffs for all the seller and all bidders.

In the simplest possible setting -namely, symmetric independent private values, as we will describe below- all these basic auction formats yield efficiency, since the bidder with the highest willingness to pay wins.

Naturally, many more formats are possible. Open and closed auctions can be combined, and more complex rules to establish the price paid by the winner may be used.

\section{(ii) Bidder valuations}

A second key aspect defining the auctioning context is how bidders value the object(s) on sale, and how those valuations relate to one another. A bidder will behave differently, and the auction's outcome will thus change, if her willingness to pay is completely unrelated to, and when it is very much linked to, her rivals' valuations. As we will describe below, Milgrom and Wilson's contributions greatly improved our understanding of how auctions work differently when the context varies along this dimension.

In one extreme case, there are common values: the object(s) have an "objective" value that is thus the same for everyone. However, bidders do not know that value, but only receive a signal of what it may be. Informally, we may interpret that signal as bidders having an estimate of the objective value. Assume, for example, that bidders compete for drilling rights in a given oil or gas tract. If all bidders have equally efficient drilling technologies, the value of those rights will be the same for all of them as well. However, the tracts' production is uncertain. Wilson (1969, 1977) formally studied the mineral rights model, inspired by this precise application. Similar settings emerge when financial assets are sold, as happens with treasury bills or stocks in IPOs. In all these cases, if a bidder receives information about her rival's signals, she will probably revise her own estimate of the object's value.

A fundamental aspect of common value auctions is the winner's curse. Take the drilling rights auction described above. Standard auction formats would make 
bidders more aggressive when they have higher estimates of the rights' value. The winner, then, will be the bidder with the highest signal of the objective value. The highest signal, though, will probably lead to an overestimation. In other words, if a bidder wins, it is because her rivals have lower estimates of the objective value. Winning, then, brings bad news.

If bidders do not take this into account when choosing their bids, they run the risk of paying more than the objective value. In equilibrium, though, the winner's curse will be anticipated, and bidders will behave more conservatively5.

The extreme opposite case to common values is that where bidders' valuations are completely idiosyncratic. In a setting of private values, bidders' willingness to pay for the object(s) on sale would not change even if she received information about her rivals' valuations. This would apply, for example, to items that are consumed or used individually and have no objective resale value.

Since Vickrey (1961), private value auctions have been studied extensively in the literature. A striking result obtained by Riley and Samuelson (1981) and Myerson (1981), the Revenue Equivalence Theorem, states that any auction format that makes the highest-valuation bidder win will yield the exact same expected revenue for the seller. This is valid only under private values when bidders are risk-neutral, ${ }^{6}$ and it applies in particular to the four single-object basic auction formats mentioned above.

Common and private values are extreme cases. In many settings, bidders' valuations have a private-value and a common-value component. Knowing her rivals' valuations may make a bidder revise her own willingness to pay -at least, as consequence that her estimate of the object's resale value changes- but it is not necessarily true that there is a common value to all of them. Intermediate settings are a bit more complex and were thoroughly studied in Milgrom \& Weber (1982).

Milgrom (1981) and Milgrom \& Weber (1982) introduced the concept of affiliation. In particular, the private signals that bidders have about the value of the object, and any information the seller has about that value, are affiliated. Affiliation is a strong form of positive correlation. If a bidder receives a higher signal, then, not only will he have a larger willingness to pay privately, but he will also expect other bidders to have received higher signals as well. Milgrom \& Weber (1982)

5 For a very clear description of the winner's curse, see Milgrom (1989).

6 For a precise statement of the theorem, see Krishna (2009), ch. 3. 
thus generalized the previous work on private and common values, obtained the equilibria of all basic auction formats and compared them.

One particularly important result in that comparison is the linkage principle. Intuitively, it states that the auction formats that allow bidders to learn and aggregate their information better will yield higher expected revenue for the seller. How cautious they will be may depend on the auction format. For example, an English auction allows bidders to gather information about her rival's signals through their bids. In a sealed-bid auction, on the contrary, that is impossible. More aggressive bids will then follow in the former. Applying the same principle, it can be shown that the seller has an incentive to reveal any information she may have about the object's value.

There are other bidder characteristics that may influence any auction format's result. For example, bidders may be risk averse or risk neutral. The signals they receive that determine their valuations may be drawn from cumulative distributions that are symmetric or asymmetric. In the latter case, some bidders may be stronger than others, so that their valuations are expected to be higher. In essence, then, any characteristic that may influence bidder preferences may be key to the conclusions we derive about how attractive each auction format turns out to be.

\section{(iii) Auctioning a single or multiple objects}

Most of our examples so far have referred to auctions of a single, indivisible object. However, in many cases several objects are allocated in the same auctioning process (e.g. spectrum licenses) or the object is divisible (e.g. financial assets). Again, Milgrom and Wilson's contributions along these lines were key both in theory and, as we will see, in practice.

Multiple-object auctions pose new problems that, naturally, combine with those discussed above. For instance, it should be decided whether all objects will be allocated simultaneously or sequentially.

Let us take first the case where a divisible object is being allocated. Different auction formats may be used. For example, winning bidders may pay the same unit price (uniform-price auctions) or, alternatively, each bidder may pay the price she bid (discriminatory auctions). ${ }^{7}$ Wilson (1979) studied those formats.

7 The same formats may be used when multiple, identical and indivisible units are auctioned. There are many other possible formats. See Krishna (2009), ch.12. 
Usually, bidders would want a larger portion if the price is more attractive. Then, they can submit demand functions, as in the case of financial assets -or supply functions, as when electricity is purchased from generators. In addition, the total volume being allocated may depend on the total demand/supply received by the auctioneer. ${ }^{8}$ Wilson (1979)'s seminal analysis of share auctions identified a new key effect. Bidders, as firms with market power in usual markets, have an incentive to "reduce" their demands in order to raise the prices they will obtain in the auction. Wilson $(2002,2008)$ provided a formal study of electricity markets, and how supply-function competition operates in them.

Multi-unit auctions of indivisible objects may add complex new issues. ${ }^{9}$ The objects being allocated may be substitutes or complements of one another, so it may be the case that a bidder's willingness to pay depends on the whole set of objects she is awarded. In the 1990's auction theory did not have a precise recommendation as to which auction format to use in these cases. However, as we will see, it provided the background from which theorists, with crucial roles played by Milgrom and Wilson, helped develop new, useful auction formats for allocating multiple interrelated objects.

We have so far described the variety of settings where auctions may be run, and how the results and attractiveness of each format crucially depend on the exact context. Still, we have not been exhaustive. Several other issues are relevant and create an even larger diversity of contexts in which each auction format's performance may be studied.

All the contexts we have described so far have taken the number of bidders that take part in the auction as given. However, attracting sufficient bidders is crucial to the auction's performance. Indeed, Bulow and Klemperer (1996) showed that in many settings, any auction with $N$ bidders, however sophisticated, will yield lower revenue than a standard auction with $N+1$ bidders, thus stressing the prominent role of entry to ensure a competitive outcome in the auction. There is a literature on endogenous entry in auctions that stems from Samuelson (1985) and McAfee \& McMillan (1987).

Another phenomenon that may alter conclusions and comparisons between auction formats is bidder collusion. This issue is key when designing auctions in

8 A comprehensive analysis of supply-function competition can be found in Klemperer \& Meyer (1989).

9 An excellent source on this issue is Milgrom (2004). 
practice and has been examined by a number of contributions to the literature. See Marshall \& Marx (2012) for a summary of the key problems associated to collusion.

Of course, entry and collusion issues are not exclusive to auctions. As very clearly stated in Klemperer (2002), "The most important issues in auction design are the traditional concerns of competition policy -preventing collusive, predatory, and entry-deterring behavior."

In many settings the auction is run by an agent of the seller or buyer, and both parties' interests may not be perfectly aligned. Then, corruption may arise, in the sense that the auctioneer may extract rents from bidders in exchange for tilting the auction in their favor. This is particularly important for public procurement ${ }^{10}$.

It may also be the case that the seller's objectives differ from pure revenue maximization or pure efficiency. For example, the seller may not be indifferent as to who may win the auction. Governments may prefer awarding contracts to local bidders, since the pay more taxes locally. This is sometimes called favoritism, and may be modelled as an auction where favored bidders' profits matter to the seller ${ }^{11}$.

Recent literature in acutions has focused on auctions with securities. In this setting, bidders make bids in terms of contracts, offering a payment tied to the auctioned good revenue. Securities are particularly relevant in the allocation of oil drilling tracts, telecommunication spectrum, electricity, corporate takeovers, and the allocation of projects whose revenue is observable ${ }^{12}$

Multiple auction settings have been studied under the presence of securities. From a theoretical perspective DeMarzo, Kremer \& Skrzypacz (2005) characterize the sensitivity of standard securities to the winners' type, thus, increasing the revenue of the seller. Several papers follow this literature ${ }^{13}$.

Finally, we must mention that a substantial literature studies auctions empirically ${ }^{14}$ and experimentally ${ }^{15}$.

10 See Lengwiler \& Wolfstetter (2006) or Arozamena \& Weinschelbaum (2011a) for a survey.

11 See Arozamena \& Weinschelbaum (2011b) for a survey.

12 See Skrzypacz (2013) for a comprehensive literature review.

13 See Liu and Bernhardt (2019) or Hernandez-Chanto \& Fioriti (2019) for recent extensions of auctions with securities.

14 Athey \& Haile (2006) provide a detailed summary of the empirical approach to auctions. See also Gabrielli (2018) for a survey of structural estimation in auctions.

15 See Kagel (1995) and several chapters in Plott \& Smith (2008) for surveys. 


\section{NEW AUCTION FORMATS}

In addition to, and in close connection with their theoretical contributions, Milgrom and Wilson took part in some of the most important practical applications of auction theory in the last few decades. These applications implied creating, developing, and testing new auction formats, particularly adequate for the specific contexts where they would be used.

In the early 1990's, the U.S. Federal Communications Commission decided to explore using auctions to allocate spectrum for personal communications, which up to then had been allocated by different, less satisfactory means. In 1994, as proposed by Milgrom, Wilson and R.Preston McAfee, the FCC sold licenses for spectrum use through simultaneous, multiple-round auctions. In such format, all licenses are auctioned at the same time. In each round, buyers may submit bids for one or many licenses, and after each round a provisional winner for each object is announced. Bids can raise standing prices in the next round, and so on. The process ends when none of the standing prices is beaten by a new bid. These simultaneous auctions provide information to bidders on which objects they are winning and, additionally, as other open formats, on rivals' willingness to pay 16.

The FCC's first use of this format was a complete success. Simultaneous auctions of this kind were then extensively used worldwide for spectrum allocation, raising billions of dollars in revenue. It is hard to find another instance of theorists having such an immediate impact in practical market design, particularly in such a scale ${ }^{17}$.

The precedent thus set was then followed in other markets and in other rounds of spectrum allocation. New auctions were developed to improve upon the original simultaneous multiple-round format. In that format, bidders still face the exposure problem: they are not entirely sure of the exact set of objects they have won until the end. They may, for example, be left winning one object alone that is not valuable without a complement. The combinatorial clock auction, described in Ausubel, Cramton \& Milgrom (2006), allows participants to make bids for packages of objects. This creates computational issues but eliminates the exposure problem. Since its first use in the U.K. in 2008, many countries adopted this format for spectrum allocation.

\footnotetext{
16 There is an activity rule that forces bidders to make bids for objects they are interested in, instead of just waiting for rivals to bid and enter at later stages. Without such a rule, the auction would not allow bidders to learn about rivals' valuations. 
The wave of new format development for multiple-object auctions has not stopped. In 2017, the FCC run an incentive auction described in Milgrom et al. (2012), Leyton-Brown, Milgrom \& Segal (2017) and Milgrom (2017, 2019). The problem faced by the FCC was not how to allocate spectrum, but rather how to reallocate it from its current holders (TV broadcasters) to mobile broadband providers. The design proposed by Milgrom and others run first a reverse auction where the price that would be paid to TV broadcasters was determined, and a forward auction, that allocated the released spectrum to its new users. Both stages were interdependent, and their relation presented significant computational challenges. The FCC managed to reallocate a substantial range of spectrum and raised billions of dollars in the process.

The original FCC auctions in the 1990's thus initiated a trend that persists today. New problems arise, and lead to an interplay between theory and practice that yields new auction formats and better theoretical understanding of how auctions work in new, more complex settings. Another instance where this happened is the bank run that lead to the creation, by Paul Klemperer, of the product-mix auction, described in Klemperer (2010) and used to purchase toxic assets in the U.S. after the financial crisis.

A similar form of development occurred with matching theory, ${ }^{18}$ where practical problems -e.g. the allocation of doctors to hospitals, students to school vacancies or kidneys to those needing a transplant- has greatly benefited both theory and practice. Milgrom has contributed to this field by studying matching with contracts (see Hatfield \& Milgrom, 2005). Auctions and matching, as well as other, related topics, have come to form the new field of market design, that encompasses this view of allowing economists to work as "engineers" when design can improve the workings of new or existing markets that do not perform satisfactorily with their current rules of operation ${ }^{19}$.

\section{OTHER CONTRIBUTIONS}

Both Paul Milgrom and Robert Wilson made substantial, deep contributions to other areas of game and economic theory and practice, beyond the strict domain of auctions. We briefly select just a few of the most celebrated contributions below.

18 Two pioneers in this area, Alvin Roth and Lloyd Shapley, received the Nobel prize in 2012.

19 See Roth (2002). 
First, both authors studied issues relevant to financial markets, particularly those related to the role of information. Milgrom \& Stokey (1982) proved the classic no-trade theorem. In a nutshell, it states that there can be no trade based just on asymmetries of information between trading parties. If some of the traders have better information, others, less informed traders will make inferences from the former's willingness to trade and adjust their valuations accordingly. Then, none of the parties will strictly gain from trading. Wilson (1985) provided a study, based on double auctions, of information aggregation in securities markets.

We have already mentioned Wilson's analysis of electricity markets. Wilson (1993) made a detailed, both theoretical and practical analysis of nonlinear pricing policies. Such policies are key for setting tariffs in utility markets, and Wilson's analysis has proved relevant both to firms and regulators.

On a more theoretical level, both authors generated key developments and results for game theory in general. Kreps \& Wilson (1982a) introduced sequential equilibrium, which then became a standard equilibrium concept for dynamic games of incomplete information. Many important issues in information economics -e.g. signaling, reputation, strategic information transmission in general- are modelled as games within that category, so the new equilibrium concept provided solid grounding for their analysis.

Kreps and Wilson (1982b) pioneered the study of reputation in games. Motivated by the classic chain store paradox presented by Selten (1978), they showed how even small information asymmetries can lead players to try to develop a reputation for aggressive play. Kreps et al. (1982) followed a similar approach to study the possibility of cooperative play in the finitely repeated prisoner's dilemma.

Milgrom \& Shannon (1994), in a highly influential paper, introduced and developed monotone comparative statics tools. These allow for comparative statics exercises in a general class of problems and models where there may be no unique solution or equilibrium. The application of these tools has been widespread. When used in problems with uncertainty, they have led to a generalization of the usual single-crossing properties in information economics.

Finally, Milgrom's contributions with Bengt Holmström ${ }^{20}$ yielded substantial results in the study of incentives and contracts. Holmström \& Milgrom

20 Holmström received the Nobel prize jointly with Oliver in 2016 precisely for their contributions to contract theory. 
(1987) studied principal-agent relationships that extend over time and provided key insights on intertemporal incentives. Holmström \& Milgrom (1991)'s influential analysis analyzed the problems faced by a principal when providing incentives to an agent that performs several different tasks.

\section{CONCLUSIONS}

Paul Milgrom and Robert Wilson have made multiple contributions to the economics. In a wide range of topics, from auction theory to contracts and incentives, they were able to shape the current state of the art in economic theory. Furthermore, they linked that theory to applied work in market design, thereby helping create a new field that has successfully blended theory, experiments, empirical techniques and practical institutional design. Their work in the field changed the way auctions were performed and influenced auction practice worldwide.

It should also be noted that, in addition to winning the Nobel prize himself, Robert Wilson was the thesis advisor of three Nobel laureates as well: Bengt Holmström, Paul Milgrom and Alvin Roth. Needless to say, this is no coincidence, and attests to the fundamental influence Wilson and his advisees have had on economics.

Finally, taking a long-term perspective, this year's laureates provide additional evidence of the profound impact that the introduction of game-theoretic tools into economics has had on the discipline. Since 1994, the Nobel prize has been awarded nine times either for advances in game theory or for progress that resulted from its direct application.

\section{REFERENCES}

Arozamena, L., \& F. Weinschelbaum (2011a). Mecanismos de contratación pública y corrupción. In F. Navajas \& A. Porto (Eds.), Progresos en economía del sector público, (pp. 145-173). Buenos Aires: EDICON.

Arozamena, L., \& Weinschelbaum, F. (2011b). Favoritismo en subastas. In L. Arozamena \& F. Weinschelbaum (Comp.). Progresos en teoría de juegos y sus aplicaciones, (pp. 7-29). Buenos Aires: Temas Grupo Editorial.

Athey, S., \& Haile, P. A. (2006). Empirical models of auctions. In R. Blundell; W. N. Newey, \& T. Persson (Eds.). Advances in economics and econometrics. Recuperado de https://assets.cambridge.org/97805218/71532/ excerpt/9780521871532_excerpt.pdf 
Ausubel, L., Cramton, P., \& Milgrom, P. (2017). The Clock-Proxy Auction: A Practical Combinatorial Auction Design. In M. Bichler \& J. Goeree (Eds.). Handbook of Spectrum Auction Design (pp. 120-140). Cambridge: Cambridge University Press. doi:10.1017/9781316471609.007

Binmore, K., \& Klemperer, P. (2002). The Biggest Auction Ever: The Sale of the British 3G Telecom Licences. The Economic Journal, 112(478), C74-C96. Recuperado de http://www.jstor.org/stable/798361

Börgers, T., \& Krahmer, D. (2015). An introduction to the theory of mechanism design. New York: Oxford University Press.

Bulow, J., \& Klemperer, P. (1996). Auctions Versus Negotiations. The American Economic Review, 86(1), 180-194.

Cassidy, R. (1967). Auctions and auctioneering. Bekerley, California: University of California Press.

DeMarzo, P. M., Kremer, I., \& Skrzypacz, A. (2005). Bidding with securities: Auctions and security design. American Economic Review, 95(4), 936-959.

Gabrielli, M. F. (2018). Análisis estructural de datos de subastas. In H. Ahumada, M.F. Gabrielli, M. Herrera \& W. Sosa Escudero. Una nueva econometría. Bahía Blanca: EdiUNS.

Hatfield, J. \& Milgrom, P. (2005). Matching with contracts. American Economic Review, 95(4), 913-935.

Hernandez-Chanto, A., \& Fioriti, A. (2019). Bidding securities in projects with negative externalities. European Economic Review, 118(C), 14-36.

Holmström, B., \& Milgrom, P. (1987). Aggregation and linearity in the provision of intertemporal incentives. Econometrica, 55(2), 303-328.

Holmström, B., \& Milgrom, P. R. (1991). Multitask principal-agent analyses: Incentive contracts, asset ownership, and job design. Journal of Law, Economics and Organization, 7(24), 24-52.

Kagel, J. (1995). Auctions: A survey of experimental research. In J. Kagel \& A. Roth, Handbook of Experimental Economics. Princeton, New Jersey: Princeton University Press

Kagel, J. (1995). Auctions: A Survey of Experimental Research. In J. Kagel, \& A. Roth (Eds.). The Handbook of Experimental Economics (pp. 501-586). Princeton, New Jersey: Princeton University Press. doi:10.2307/j.ctvzsmff5.11 Klemperer, P. (2002). What really matters in auction design. Journal of Economic Perspectives, 16(1), 169-189.

Klemperer, P. (2010). The product-mix auction: A new auction design for differentiated goods. Journal of the European Economic Association, 8(2-3), 526-536.

Klemperer, P., \& Meyer, M. A. (1989). Supply function equilibria in oligopoly under uncertainty. Econometrica, 57(6), 1243-1277. 
Kreps, D., Milgrom, P., Roberts, J., \& Wilson, R. (1982). Rational cooperation in the finitely repeated prisoners' dilemma. Journal of Economic Theory, 27(2), 245-252.

Kreps, D., \& Wilson, R. (1982a). Sequential equilibria. Econometrica, 50(4), 863-894.

Kreps, D., \& Wilson, R. (1982b). Reputation and imperfect information. Journal of Economic Theory, 27(2), 253-279.

Krishna, V. (2009). Auction theory (2nd ed.). Cambridge: Academic Press.

Leyton-Brown, K., Milgrom, P., \& Segal, I. (2017). Economics and computer science of a radio spectrum reallocation. Proceedings of the National Academy of Sciences, 114(28), 7202-7209.

Liu, T., \& Bernhardt, D. (2019). Optimal equity auctions with two-dimensional types. Journal of Economic Theory, 184 (104913). Recuperado de https:// doi.org/10.1016/j.jet.2019.06.009

Marshall, R. C., \& Marx, L. M. (2012). The economics of collusion: Cartels and bidding rings. Cambridge, Mass: MIT Press.

McAfee, R. P., \& McMillan, J. (1987). Auctions with entry. Economics Letters, 23(4), 343-347.

Milgrom, P. (1981). Rational expectations, information acquisition, and competitive bidding. Econometrica, 49(4), 921-943.

Milgrom, P. (1989), Auctions and bidding: a primer. Journal of Economic Perspectives, 3(3), 3-22.

Milgrom, P. (2004). Putting auction theory to work. United Kingdom: Cambridge University Press.

Milgrom, P. (2017). Discovering prices. New York: Columbia University Press.

Milgrom, P. (2019). Auction market design: Recent innovations. Annual Review of Economics, 11, 383-405. Recuperado de https://doi.org/10.1146/ annurev-economics-080218-025818

Milgrom, P. R., Ausubel, L., Levin, J., \& Segal, I. (2012). Incentive Auction Rules Option and Discussion. Appendix to the FCC's Notice of Proposed Rulemaking, (GN Docket No 12-268). Washington D.C.: Federal Communications Commission.

Milgrom, P. R., \& Shannon, C. (1994). Monotone comparative statics. Econometrica, 62(1), 157-180.

Milgrom, P. R., \& Stokey, N. (1982). Information, trade and common knowledge. Journal of Economic Theory, 26(1), 17-27.

Milgrom, P. R., \& Weber, R. J. (1982). A theory of auctions and competitive bidding. Econometrica, 50(5), 1089-1122.

Myerson, R. B. (1981). Optimal auction design. Mathematics of Operations Research, 6(1), 58-73.

Plott, C. R., \& Smith, V. L. (Eds.). (2008). Handbook of experimental economics results (Vol. 1). North Holland: Elsevier. 
Riley, J. G., \& Samuelson, W. F. (1981). Optimal auctions. American Economic Review, 71(3), 381-392.

Roth, A. E. (2002). The economist as engineer: Game theory, experimentation, and computation as tools for design economics. Econometrica, 70(4), 13411378 .

Royal Swedish Academy of Sciences (2020). Improvements to auction theory and inventions of new auction formats, Scientific Background on the Sveriges Riksbank Prize in Economic Sciences in Memory of Alfred Nobel 2020. Recuperado de www.nobelprize.org.

Samuelson, W. F. (1985). Competitive bidding with entry costs. Economics Letters, 17(1-2), 53-57.

Selten, R. (1978). The chain store paradox. Theory and Decision, 9(2), 127-159.

Skrzypacz, A. (2013). Auctions with contingent payments - an overview. International Journal of Industrial Organization, 31(5), 666-675.

Wilson, R. (1969). Competitive Bidding with Disparate Information. Management Science, 15(7), 446-448.

Wilson, R. (1977). A bidding model of perfect competition. Review of Economic Studies, 44(3), 511-518.

Wilson, R. (1979). Auctions of shares. The Quarterly Journal of Economics, 93(4), 675-689.

Wilson, R. (1985). Incentive Efficiency of Double Auctions. Econometrica, 53(5), 1101-1115. doi: $10.2307 / 1911013$

Wilson, R. (1993). Nonlinear pricing. United States: Oxford University Press.

Wilson, R. (2002). Architecture of power markets. Econometrica, 70(4), 12991340.

Wilson, R. (2008). Supply function equilibrium in a constrained transmission system. Operations Research, 56(2), 369-382.

Vickrey, W. (1961). Counterspeculation, auctions, and competitive sealed tenders. The Journal of Finance, 16(1), 8-37.

(C) 2021 por los autores; licencia no exclusiva otorgada a la revista Estudios económicos. Este artículo es de acceso abierto y distribuido bajo los términos y condiciones de una licencia Atribución-No Comercial 4.0 Internacional (CC BY-NC 4.0) de Creative Commons. Para ver una copia de esta licencia, visite http://creativecommons.org/licenses/by-nc/4.0 